\title{
Prevalence and stabilizing trends in overweight and obesity among children and adolescents in China, 2011-2015
}

Jiguo Zhang, Huijun Wang, Zhihong Wang, Wenwen Du, Chang Su, Ji Zhang, Hongru Jiang, Xiaofang Jia, Feifei Huang, Yifei Ouyang, Yun Wang and Bing Zhang

\begin{abstract}
Background: The prevalence of childhood overweight and obesity in developed countries appears to be plateauing. The purpose of this study was to provide the most recent data on the prevalence and trends in overweight and obesity among Chinese children and adolescents from 2011 to 2015.
\end{abstract}

Methods: We used data collected in the China Health and Nutrition Survey (CHNS) and China Nutritional Transition Cohort Study (CNTCS). We used two waves of the survey in 12 provinces conducted in 2011 (aged 7-18 years; $n=1458$ ) and 2015 (aged $7-18$ years; $n=1084$ ) to perform a trend analysis. We used data collected in 15 provinces (aged $7-18$ years; $n=1617$ ) to estimate the prevalence of overweight and obesity among Chinese children and adolescents in 2015.

Results: In 2015, based on the Working Group for Obesity in China (WGOC) criteria, the prevalence of overweight and obesity were $14.0 \%(95 \% \mathrm{Cl}, 11.6-16.3)$ and $10.5 \%(95 \% \mathrm{Cl}, 8.4-12.6)$ in boys, and $9.7 \%$ (95\% Cl, 7.7-11.8) and 7.1\% (95\% Cl, 5.2-8.9) in girls, respectively. The increase in BMI z-scores from 2011 to 2015 was statistically significant among adolescents $(p=0.0083)$, but not among children. No significant changes were observed in prevalence of overweight and obesity between 2011 and 2015, excepting adolescents aged $12-18$ years $(p=0.0086)$.

Conclusions: Since 2011, overweight has remained stable, and obesity has stabilized in children, though not in adolescents. Although levels of childhood overweight and obesity in China are not high compared to other developed countries, they remain concerning enough that effective policies and interventions need to be sustained and intensified for lowering rates of childhood overweight and obesity.

Keywords: Adolescents, Children, China, Obesity, Overweight

\section{Background}

Childhood obesity is a serious public health problem that requires urgent attention [1]. Today many children are growing up in an obesogenic environment that encourages weight gain and obesity [2]. It is necessary and important to build monitoring systems to regularly track the prevalence of childhood obesity, thus providing data for policy development and in offering evidence of the impact and effectiveness of interventions [1].

* Correspondence: zzhangb327@aliyun.com

National Institute for Nutrition and Health, Chinese Center for Disease Control and Prevention, No.29 Nanwei Road, Beijing 100050, China
Prevalence of obesity has increased substantially in children and adolescents around the world, including in China $[3,4]$. The childhood overweight and obesity epidemic in China began in 1985, and at that time, the prevalence of overweight (1.1\%) and obesity $(0.1 \%)$ was very low [5]. Afterwards, rapid economic development in China caused transitions in nutrition and physical activity behavior, which contributed to a rapid increase in the prevalence of overweight and obesity [6-8]. In 2012, the national overweight and obesity prevalence of children aged $6-17$ years were $9.6 \%$ and $6.4 \%$, respectively [9]. However, recent evidence suggests that a plateaued trend or even a decrease in childhood overweight

(C) The Author(s). 2018 Open Access This article is distributed under the terms of the Creative Commons Attribution 4.0 International License (http://creativecommons.org/licenses/by/4.0/), which permits unrestricted use, distribution, and 
and obesity is underway in many developed countries. For example, in Germany, researchers observed a further stabilization of overweight and obesity prevalence rates for all age groups and a decrease in rates for younger ages (47.99 years, 8-11.99 years) [10]. Similarly, stabilized trends have been observed in other countries, such as US children aged 6 to 11 years [11], UK children aged 2 to 10 years [12], Australian primary school children [13], and Canadian children [14].

Many trend analyses have shown a continuously rising prevalence of obesity/overweight in China, with more rapid increases in toddlers and boys than in their counterparts, as well as in rural versus urban areas $[4,15-20]$. However, most previous studies were based either on earlier surveys or on provincial data. In this study, our objectives were to provide the most recent estimates of obesity and overweight prevalence among Chinese children and adolescents in 2015, to evaluate trends in BMI $\mathrm{z}$-scores and to examine the trends in prevalence of overweight and obesity for the 5 years of two adjacent surveys in 2011 and 2015. Additionally, we present more detailed trend analyses by age, sex, living area and geographic region.

\section{Methods}

\section{Study design and subjects}

We used data collected in the China Health and Nutrition Survey (CHNS) and China Nutritional Transition Cohort Study (CNTCS). CHNS was an ongoing large-scale, longitudinal, household-based survey of 10 waves (1989-2015) $[21,22]$. Beginning in 2011, the CHNS covered 12 provinces that varied in demography, geography, economic development, and public resources. In 2015, the CNTCS began in the additional provinces of Zhejiang, Shanxi, and Yunnan. In each province, a multistage, stratified, random cluster sampling design was used to ensure a suitable representation of the population. Two cities and four counties were selected by income (low, middle, and high). Four communities from each city/county were selected randomly; in each community, 20 households were randomly selected and followed in ten subsequent waves. In some cases, new households were recruited to substitute for those who migrated out of the community for different reasons.

The trend analysis was based on two waves of the survey in 12 provinces conducted in 2011 and 2015. Our sample included children and adolescents aged 7 to 18 years from each family included in the two rounds of survey. There were 1458 and 1084 children and adolescents with complete demographic and physical examinations, respectively. We used data combining CHNS with CNTCS collected in 15 provinces to estimate the prevalence of overweight and obesity among children and adolescents in 2015.

\section{Measures and definition}

Anthropometrical measurements were conducted by welltrained health workers who followed a reference protocol recommended by the World Health Organization (WHO) [23]. Height was measured to the nearest $0.1 \mathrm{~cm}$ without shoes using a portable SECA206 wall-mounted metal tape, and weight was measured to the nearest $0.1 \mathrm{~kg}$ with lightweight clothing on a beam SECA 880 in 2011 and a TANITA BC601 in 2015. Both the scales and stadiometers were calibrated before use. Body mass index (BMI) was calculated as weight in kilograms divided by height in meters squared.

The sex- and age-specific BMI cutoff points recommended by the International Obesity Task Force (IOTF) [24], WHO [25], and Working Group for Obesity in China (WGOC) were used to define overweight and obesity. The former two sets of criteria have been used internationally to assess and compare childhood overweight and obesity in different countries. Considering the differences in body composition across different ethnic groups, the WGOC, which was organized by the International Life Science Institute Focal Point in China, conducted an analysis of BMI of children and adolescents aged 7-18 years. Overweight was defined as BMI $>85$ th percentile but $\leq 95$ th percentile, relative to gender and age, whereas obesity was defined as BMI >95th percentile, and a new BMI classification reference was recommended by the WGOC in 2004 [26]. This standard is the most appropriate one that showed its superiority in both prospectively and actuality, and was consistent with the Eastern Asia ethnic characteristics of body fatness growth [27]. BMI-for-age z-score is a quantitative measure of the deviation of a specific BMI value from the mean of that population, and was calculated with the WHO (WHO 2007) references.

\section{Ethical approval}

All subjects' parents gave written informed consent for their children's participation in the survey. The CHNS was approved by the Institutional Review committees of the University of North Carolina at Chapel Hill and the National Institute for Nutrition and Health, Chinese Center for Disease Control and Prevention (No. 201524).

\section{Statistical analysis}

The primary data analysis was conducted in 2017. We presented prevalence estimates for overweight and obesity in different survey years according to age, gender, living area and geographic region groups. Living area of urban and rural was based on the Chinese administrative division. A line running along the Qinling Mountains and Huaihe River was considered as the natural boundary between north and south of geographic region in China. 
$\mathrm{T}$ tests were applied to test differences between groups and trends for BMI z-scores. Chi-square analyses were conducted to assess differences in prevalence of overweight and obesity for categorical variables. All statistical analyses were performed using version 9.2 of the SAS software package (SAS Institute, Inc. Cary, NC, USA). Statistical significance was defined as $P<0.05$.

\section{Results}

\section{Prevalence of overweight and obesity}

Table 1 shows the prevalence of overweight and obesity among Chinese children and adolescents aged 7-18 years in 2015. Using IOTF, WHO, and WGOC criteria, the prevalence of overweight and obesity were $13.1 \%$ (95\% CI, 11.514.8 ) and $5.7 \%$ (95\% CI, 4.5-6.8), 15.5\% (95\% CI, 13.7-17.2) and $8.8 \%$ (95\% CI, 7.4-10.2), 11.9\% (95\% CI, 10.4-13.5) and $8.8 \%$ (95\% CI, 7.5-10.2), respectively. We found a much higher prevalence of obesity among boys than among girls $(p<0.0001, \mathrm{p}<0.0001, p=0.0143)$. The northern children and adolescents showed higher prevalence of overweight and obesity than their southern peers, except for overweight using the WGOC criteria. In addition, the IOTF criteria found a higher prevalence of obesity among urban children and adolescents $(p=0.0458)$, the WGOC criteria found a much higher prevalence of overweight among boys than among girls $(p=0.0087)$. There was no significant difference between age groups by the three sets of criteria.

\section{Trends in BMI z-scores among children and adolescents}

Table 2 shows the mean BMI $z$-scores among Chinese children and adolescents aged 7-18 years between 2011 and 2015. The increase in BMI z-score from 2011 to 2015 was statistically significant $(p=0.0211)$. After stratifying by age group, gender, living area and region, we found a significant increase in BMI z-scores among adolescents aged $12-18 \quad(p=0.0083)$, boys $(p=0.0107)$, urban $(p=0.0173)$ and southern children and adolescents $(\mathrm{p}=0.0087)$.

\section{Trends in prevalence of overweight and obesity}

Table 3 shows the trends in prevalence of overweight and obesity among Chinese children and adolescents aged 7-18 years using the WGOC criteria between 2011 and 2015. We found no significant difference in prevalence of overweight and obesity between 2011 and 2015, except for adolescents aged 12-18 years, who had a higher prevalence of obesity in 2015 than that in 2011 $(p=0.0086)$.

\section{Discussion}

Our findings show that the prevalence of overweight and obesity have remained stable among Chinese children since 2011, but not among adolescents aged 12-18 years for whom the prevalence of obesity has significantly increased between 2011 and 2015, consistent with findings from a recent Australian study [13]. The increase and higher prevalence of obesity in adolescents is concerning given the high likelihood of BMI tracking from adolescence into adulthood [28]. Thus, adolescents should be the key target of obesity prevention.

According to two reviews, the prevalence of childhood overweight and obesity appears to have stabilized since the late 1990s in many developed countries $[29,30]$. In Asia, there was a decrease in the prevalence of overweight/obesity among Japanese schoolchildren from 2003 to 2012 [31]. In Korea, the prevalence of childhood overweight and obesity generally stabilized from 2001 to 2012 in both boys and girls [32]. In general, this stabilization in the trend has been attributed to the growing population concern about childhood obesity and continuous efforts of the family, school, community and government toward the prevention and treatment of childhood obesity [33]. As a result of these efforts, a whole series of interventions has been implemented to halt the alarming rise in the prevalence of childhood obesity, such as reducing television viewing duration and consumption of energy-dense foods, as well as increasing physical activity [33, 34].

Similarly, the Chinese government began to realize the importance of obesity control about 15 years ago, and implemented laws and regulations aimed at obesity prevention [35]. For example, China has already developed some guidelines to control general childhood obesity, such as Guidelines on Snacks for Chinese Children and Adolescents (published in 2008) and the School-age Children and Teenagers Overweight and Obesity Prevention and Control Guidelines (issued in 2007) [35]. Also, a large number of intervention programs have been initiated or were ongoing in the past 15 years, such as 'Happy 10 minutes'. The key measures of program and policy options for prevention that began during childhood may have contributed to the stabilization in prevalence of childhood overweight and obesity. It is also possible that this flattening represents a temporary lull and that without continued efforts we may again see a rise in prevalence. Further studies are needed to assess the possible reasons of the trends in overweight and obesity.

In this study, we used three different sets of criteria to estimate the prevalence of overweight and obesity among Chinese children and adolescents in 2015. Among the three sets of criteria, the WHO criteria yielded the highest prevalence of overweight and obesity, while the WGOC criteria produced the lowest overweight prevalence, and the lowest obesity prevalence was generated by the IOTF criteria. These results from the three sets of criteria were expected, considering their use of different BMI cut-points for overweight and 


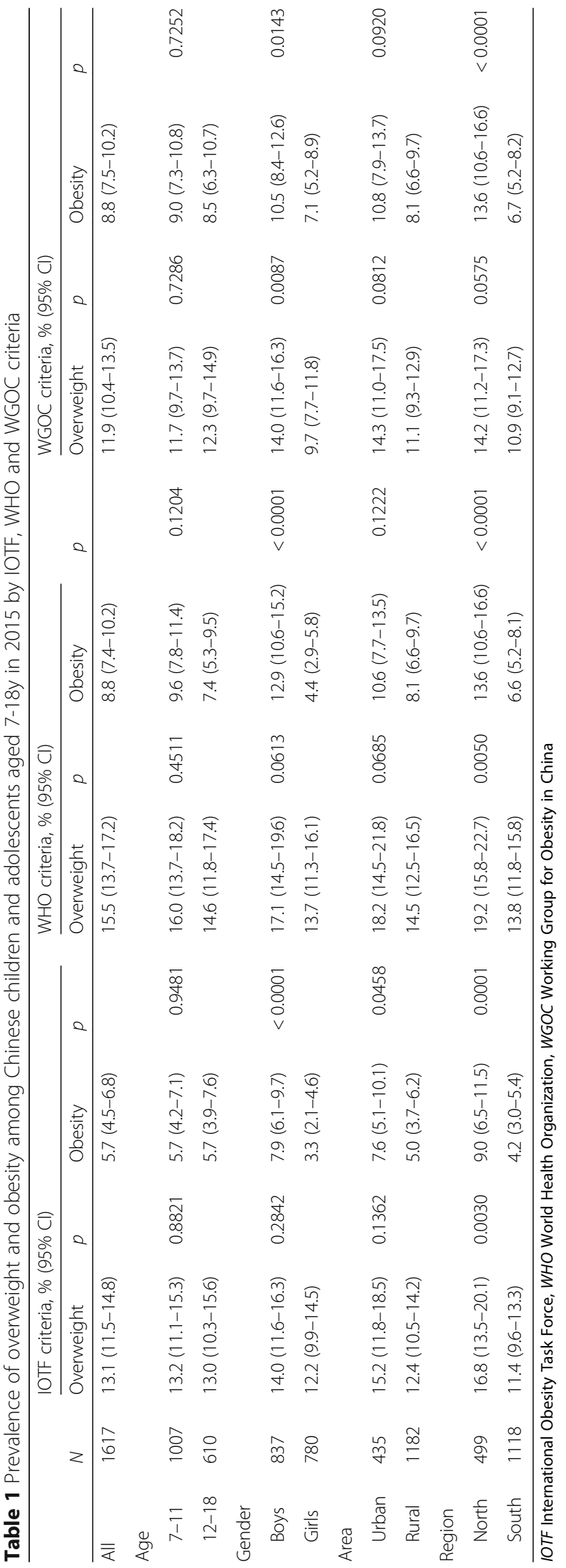


Table 2 Trends in BMI z-scores among Chinese children and adolescents aged 7-18y: 2011-2015

\begin{tabular}{clllll}
\hline & & 2011 & & 2015 & $P$ \\
& $N$ & Mean \pm SD & $N$ & Mean \pm SD & \\
\hline All & 1458 & $-0.0749 \pm 1.3632$ & 1084 & $0.0528 \pm 1.4028$ & 0.0211 \\
Age & & & & & \\
$7-11$ & 762 & $0.0421 \pm 1.5078$ & 698 & $0.0737 \pm 1.4251$ & 0.6818 \\
$12-18$ & 696 & $-0.2031 \pm 1.1726$ & 386 & $0.0150 \pm 1.3626$ & 0.0083 \\
Gender & & & & & \\
Boys & 743 & $0.0426 \pm 1.4529$ & 554 & $0.2522 \pm 1.4710$ & 0.0107 \\
Girls & 715 & $-0.1970 \pm 1.2527$ & 530 & $-0.1556 \pm 1.2968$ & 0.5700 \\
Area & & & & & \\
Urban & 440 & $0.1275 \pm 1.3571$ & 282 & $0.3732 \pm 1.3381$ & 0.0173 \\
Rural & 1018 & $-0.1625 \pm 1.3572$ & 802 & $-0.0599 \pm 1.4085$ & 0.1155 \\
Region & & & & & \\
North & 461 & $0.3738 \pm 1.3626$ & 302 & $0.4911 \pm 1.4773$ & 0.2612 \\
South & 997 & $-0.2824 \pm 1.3133$ & 782 & $-0.1165 \pm 1.3360$ & 0.0087 \\
\hline
\end{tabular}

obesity among children and adolescents. Because different criteria are used throughout the world, it can be difficult to compare rates in China with those in other countries. Nonetheless, estimates of overweight and obesity among Chinese children and adolescents tend to be lower than in developed countries $[3,11]$. However, childhood overweight and obesity is becoming a topic of great concern in China due to the higher prevalence in some provinces [36, 37] approaching that of Western countries.

In line with previous studies in China $[6,20]$, we found a gender difference in that boys showed a higher prevalence

Table 3 Trends in Prevalence of overweight and obesity among Chinese children and adolescents aged 7-18y by WGOC criteria: 2011-2015

\begin{tabular}{|c|c|c|c|c|c|c|c|c|}
\hline & \multirow{2}{*}{$\begin{array}{l}2011 \\
N\end{array}$} & \multirow{2}{*}{$\begin{array}{l}2015 \\
N\end{array}$} & \multicolumn{2}{|c|}{ Overweight } & \multirow[t]{2}{*}{ p } & \multicolumn{2}{|c|}{ Obesity } & \multirow[t]{2}{*}{$p$} \\
\hline & & & 2011 & 2015 & & 2011 & 2015 & \\
\hline All & 1458 & 1084 & 10.6 & 11.8 & 0.3507 & 8.4 & 9.6 & 0.3113 \\
\hline \multicolumn{9}{|l|}{ Age } \\
\hline $7-11$ & 762 & 698 & 10.6 & 11.0 & 0.8051 & 11.4 & 9.7 & 0.2993 \\
\hline $12-18$ & 696 & 386 & 10.6 & 13.2 & 0.2034 & 5.2 & 9.3 & 0.0086 \\
\hline \multicolumn{9}{|l|}{ Gender } \\
\hline Boys & 743 & 554 & 13.6 & 13.7 & 0.9483 & 9.2 & 11.7 & 0.1296 \\
\hline Girls & 715 & 530 & 7.6 & 9.8 & 0.1579 & 7.7 & 7.4 & 0.8255 \\
\hline \multicolumn{9}{|l|}{ Area } \\
\hline Urban & 440 & 282 & 14.1 & 13.8 & 0.9214 & 9.8 & 13.1 & 0.1621 \\
\hline Rural & 1018 & 802 & 9.1 & 11.1 & 0.1661 & 7.9 & 8.4 & 0.7001 \\
\hline \multicolumn{9}{|l|}{ Region } \\
\hline North & 461 & 302 & 15.0 & 15.9 & 0.7283 & 13.9 & 16.6 & 0.3111 \\
\hline South & 997 & 782 & 8.6 & 10.2 & 0.2482 & 5.9 & 6.9 & 0.3966 \\
\hline
\end{tabular}

of obesity than girls. Differences in genetic and environmental factors could partly contribute to the gender differences in overweight and obesity. Moreover, there exists a traditional preference for boys in Chinese society, especially in rural areas [20]. Owing to this preference, boys are likely to enjoy more of the family's resources and have less work than girls. In addition, obesity is often viewed as a characteristic of good health in boys [18]. On the other hand, girls are expected to maintain a slender shape, and as a result they pay more attention to weight control $[6,18]$.

In the present study, no significant urban-rural disparity was observed except the obesity seen using IOTF criteria, which was inconsistent with previous results showing that urban childhood had a higher prevalence of overweight and obesity than rural counterparts [6, 18]. In the past 15 years, the pace of the obesity epidemic in rural areas has been much faster than in urban areas, and thus the urban-rural disparity of obesity prevalence has been getting narrower, which means the burden of overweight and obesity may shift from the rich to the poor $[16,38]$. These findings could be due to economic growth and changes in lifestyle. Family income and urbanization may be linked to dietary factors, and to factors associated with sedentary behavior such as increased television watching [39]. Research indicates that as income has improved, particularly in the low- and middle-income groups, the structure of the Chinese diet has shifted away from high-carbohydrate foods toward high-fat, high-energy-density foods [40]. Therefore, policymakers and experts should develop specific interventions for obesity in rural areas, even though their obesity prevalence is still lower than that in urban areas.

In the present study, we also found a north-south disparity in the prevalence of overweight and obesity. Northern children showed a higher prevalence of overweight and obesity than their southern counterparts. Climate could serve as one explanation for this disparity. The northern region is characterized by a longer winter with the coldest temperature is approximately below $0{ }^{\circ} \mathrm{C}$. In southern cities, the winter is shorter with the coldest temperature above $0{ }^{\circ} \mathrm{C}$. As a result, individuals in northern areas might exhibit decreased physical activity, and may store more fat to resist the cold temperatures in the winter [20]. Diet is another possible explanation. A previous study reported that childhood obesity was positively associated with traditional northern dietary pattern in China, which could be partly explained by the high carbohydrate intake and lower levels of micronutrients [41].

One important limitation of our study was the lack of large sample size to obtain nationally representative results, even though the survey captured different demographic and geographical areas. Second, because this study used data from two cross-sectional surveys, the 
data can't be used to infer causality or predict future trends. Prospective studies could confirm or broaden our results. Finally, we did not analyze factors such as dietary and lifestyle habits that may affect trends in overweight and obesity.

Despite these limitations, to the best of our knowledge, this is the first study to report the most recent prevalence and stabilizing trends in overweight and obesity among Chinese children and adolescents using large survey data between 2011 and 2015. Based on the results, the government and scientific community could take appropriate measures for childhood obesity prevention. Besides, we used three different set of criteria to estimate the prevalence of childhood overweight and obesity, making international comparisons possible.

\section{Conclusion}

In summary, overweight has remained stable since 2011, and obesity has stabilized in children, but not in adolescents. Continuing research is needed to confirm these trends. Effective policies and interventions need to be sustained and intensified to lower rates of childhood overweight and obesity, even though the prevalence remains lower than developed countries.

\section{Abbreviations}

CHNS: China Health and Nutrition Survey; CNTCS: China Nutritional Transition Cohort Study; IOTF: International Obesity Task Force; WGOC: Working Group for Obesity in China; WHO: World Health Organization

\section{Acknowledgements}

The authors are grateful to the participants for their involvement in the survey. The authors also thank the team at National Institute for Nutrition and Health, Chinese Center for Disease Control and Prevention, the Carolina Population Center, University of North Carolina at Chapel Hill, and the 15 provincial Center for Disease Control and Prevention.

\section{Funding}

This research uses data from the CHNS and CNTCS. The CHNS receives funding from the $\mathrm{NIH}$ to Carolina Population Center at the University of North Carolina at Chapel Hill (NIH grant P2C HD050924, T32 HD007168) and to research grants from the NIH (R01DK104371, R01HL108427, R01 HD30880, P30 DK056350, R01 R01DK104371, R01HL108427) and the NIH Fogarty grant D43 TW009077 for financial support for the CHNS data collection and analysis files from 1989 to 2015 and future surveys. The CNTCS (13103110700015005) is supported by national finance allocation in China since 2015.

\section{Availability of data and materials}

The raw data sets supporting this article can be made available by emailing the corresponding author on reasonable request.

\section{Authors' contributions}

The authors' contributions are as follows: JGZ conducted data collection, data management, statistical analysis and interpretation, and manuscript design and writing. HJW, ZHW, WWD, CS, JZ, HRJ, XFJ, FFH, YFOY and YW conducted data collection, data management, and advised on statistical analysis. HJW and ZHW contributed to editing and proof reading of the final version of the manuscript. BZ, the corresponding author, had full access to all the data in the study and takes the primary responsibility for the final content. All authors read and approved the final version of the manuscript.

\section{Ethics approval and consent to participate}

All subjects' parents gave written informed consent for their children's participation in the survey.

The CHNS was approved by the Institutional Review committees of the University of North Carolina at Chapel Hill and the National Institute for Nutrition and Health, Chinese Center for Disease Control and Prevention.

\section{Competing interests}

The authors declare that they have no competing interests.

\section{Publisher's Note}

Springer Nature remains neutral with regard to jurisdictional claims in published maps and institutional affiliations.

Received: 2 June 2017 Accepted: 19 April 2018

Published online: 02 May 2018

\section{References}

1. Commission on Ending Childhood Obesity. Report of the commission on ending childhood obesity. Geneva: World Health Organization; 2016. http:// www.who.int/end-childhood-obesity/publications/echo-report/en/. Accessed 25 Jan 2016.

2. Washington RL. Evidence-based medicine and the obesogenic environment. J Pediatr. 2006;149(1):5-6.

3. Ng M, Fleming T, Robinson M, Thomson B, Graetz N, Margono C, Mullany EC, Biryukov S, Abbafati C, Abera SF, et al. Global, regional, and national prevalence of overweight and obesity in children and adults during 1980-2013: a systematic analysis for the Global Burden of Disease Study 2013. Lancet. 2014;384(9945):766-81.

4. Yu Z, Han S, Chu J, Xu Z, Zhu C, Guo X. Trends in overweight and obesity among children and adolescents in China from 1981 to 2010: a metaanalysis. PLoS One. 2012;7(12):e51949

5. Song Y, Wang HJ, Ma J, Lau PW, Hu P, Zhang B, Wang Z. BMl-for-age Zscore distribution shifts among Chinese children: gender disparity. Obesity (Silver Spring). 2014;22(4):1187-93.

6. Song Y, Wang HJ, Dong B, Ma J, Wang Z, Agardh A. 25-year trends in gender disparity for obesity and overweight by using WHO and IOTF definitions among Chinese school-aged children: a multiple cross-sectional study. BMJ Open. 2016;6(9):e011904.

7. Uijtdewilligen L, Waters CN, Muller-Riemenschneider F, Lim YW. Preventing childhood obesity in Asia: an overview of intervention programmes. Obes Rev. 2016;17(11):1103-15.

8. Liang YJ, Xi B, Song AQ, Liu JX, Mi J. Trends in general and abdominal obesity among Chinese children and adolescents 1993-2009. Pediatric obesity. 2012;7(5):355-64.

9. National Health and Family Planning Commission. Report on Chinese Residents' chronic diseases and nutrition (2015). Beijing: People's Medical Publishing House; 2016.

10. Kess A, Spielau U, Beger C, Gausche R, Vogel M, Lipek T, Korner A, Pfaffle R, Kiess W. Further stabilization and even decrease in the prevalence rates of overweight and obesity in German children and adolescents from 2005 to 2015: a cross-sectional and trend analysis. Public Health Nutr. 2017:20(17):3075-83.

11. Ogden $C L$, Carroll MD, Lawman HG, Fryar CD, Kruszon-Moran D, Kit BK, Flegal KM. Trends in obesity prevalence among children and adolescents in the United States, 1988-1994 through 2013-2014. JAMA. 2016:315(21):2292-9.

12. van Jaarsveld $\mathrm{CH}$, Gulliford MC. Childhood obesity trends from primary care electronic health records in England between 1994 and 2013: populationbased cohort study. Arch Dis Child. 2015;100(3):214-9.

13. Hardy LL, Mihrshahi S, Gale J, Drayton BA, Bauman A, Mitchell J. 30-year trends in overweight, obesity and waist-to-height ratio by socioeconomic status in Australian children, 1985 to 2015. Int J Obes. 2017;41 (1):76-82.

14. Rodd C, Sharma AK. Recent trends in the prevalence of overweight and obesity among Canadian children. CMAJ. 2016;188:E313-20.

15. Zhang YX, Wang ZX, Zhao JS, Chu ZH. Trends in overweight and obesity among rural children and adolescents from 1985 to 2014 in Shandong, China. Eur J Prev Cardiol. 2016;23:1314-20.

16. Song Y, Ma J, Wang HJ, Wang Z, Hu P, Zhang B, Agard A. Secular trends of obesity prevalence in Chinese children from 1985 to 2010: urban-rural disparity. Obesity (Silver Spring). 2015;23(2):448-53. 
17. Ma L, Zhu Y, Mai J, Jing J, Liu Z, Jin Y, Guo L, Chen Y. Secular trends in overweight and obesity among urban children in Guangzhou China, 20072011. Iranian J Public Health. 2015;44(1):36-42.

18. Sun H, Ma Y, Han D, Pan CW, Xu Y. Prevalence and trends in obesity among China's children and adolescents, 1985-2010. PLoS One. 2014;9(8):e105469.

19. Song $Y$, Wang HJ, Ma J, Wang Z. Secular trends of obesity prevalence in urban Chinese children from 1985 to 2010: gender disparity. PLoS One. 2013;8(1):e53069.

20. Zhai L, Dong Y, Bai Y, Wei W, Jia L. Trends in obesity, overweight, and malnutrition among children and adolescents in Shenyang, China in 2010 and 2014: a multiple cross-sectional study. BMC Public Health. 2017;17(1):151.

21. Zhang B, Zhai FY, Du SF, Popkin BM. The China health and nutrition survey, 1989-2011. Obes Rev. 2014;15(Suppl 1):2-7.

22. Popkin BM, Du S, Zhai F, Zhang B. Cohort profile: the China health and nutrition survey-monitoring and understanding socio-economic and health change in China, 1989-2011. Int J Epidemiol. 2009;39(6):1435-40.

23. WHO. Physical status: the use and interpretation of anthropometry. Report of a WHO Expert Committee. World Health Organ Tech Rep Ser. 1995;854:1-452.

24. Cole TJ, Bellizzi MC, Flegal KM, Dietz WH. Establishing a standard definition for child overweight and obesity worldwide: international survey. BMJ. 2000; 320(7244):1240-3.

25. de Onis MOA, Borghi E, Siyam A, Nishida C, Siekmann J. Development of a WHO growth reference for school-aged children and adolescents. Bull World Health Organ. 2007;85:660-7. Available at: http://www.who.int/ growthref/growthref_who_bull/en/index.html

26. Group of China Obesity Task F. Body mass index reference norm for screening overweight and obesity in Chinese children and adolescents. Zhonghua Liu Xing Bing Xue Za Zhi. 2004;25(2):97-102.

27. Ji CY, Working Group on Obesity in C. Report on childhood obesity in China (1)-body mass index reference for screening overweight and obesity in Chinese school-age children. Biomed Environ Sci. 2005;18(6):390-400.

28. Simmonds M, Llewellyn A, Owen CG, Woolacott N. Predicting adult obesity from childhood obesity: a systematic review and meta-analysis. Obes Rev. 2016:17(2):95-107.

29. Rokholm B, Baker JL, Sorensen TI. The levelling off of the obesity epidemic since the year 1999-a review of evidence and perspectives. Obes Rev. 2010; 11(12):835-46.

30. Olds T, Maher C, Zumin S, Peneau S, Lioret S, Castetbon K, Bellisle, de Wilde J, Hohepa M, Maddison R, et al. Evidence that the prevalence of childhood overweight is plateauing: data from nine countries. Int J Pediatr Obes. 2011; 6(5-6):342-60

31. Shirasawa T, Ochiai H, Nanri H, Nishimura R, Ohtsu T, Hoshino H, Tajima N, Kokaze A. Trends of underweight and overweight/obesity among Japanese schoolchildren from 2003 to 2012, defined by body mass index and percentage overweight cutoffs. J Epidemiol. 2015;25(7):482-8.

32. Bahk J, Khang YH. Trends in measures of childhood obesity in Korea from 1998 to 2012. J Epidemiol. 2016;26(4):199-207.

33. Miqueleiz E, Lostao L, Regidor E. Stabilisation of the trend in prevalence of childhood overweight and obesity in Spain: 2001-11. Eur J Pub Health. 2016; 26(6):960-3.

34. Wabitsch M, Moss A, Kromeyer-Hauschild K. Unexpected plateauing of childhood obesity rates in developed countries. BMC Med. 2014;12:17.

35. Wang $\mathrm{H}$, Zhai F. Programme and policy options for preventing obesity in China. Obes Rev. 2013;14(Suppl 2):134-40.

36. Zhang Y, Zhao J, Chu Z, Zhou J. Increasing prevalence of childhood overweight and obesity in a coastal province in China. Pediatr Obes. 2016; 11(6):e22-6.

37. Wu $\mathrm{H}, \mathrm{Li} \mathrm{H}$, Zong $\mathrm{X}$. The prevalence of overweight, obesity and stunting in school children aged 6-19 years in Beijing, China. Ann Hum Biol. 2016;43(6):505-9.

38. Zhang YX, Wang ZX, Zhao JS, Chu ZH. Prevalence of overweight and obesity among children and adolescents in Shandong, China: urban-rural disparity. J Trop Pediatr. 2016;62(4):293-300.

39. Lobstein T, Frelut ML. Prevalence of overweight among children in Europe Obes Rev. 2003;4(4):195-200.

40. Du S, Mroz TA, Zhai F, Popkin BM. Rapid income growth adversely affects diet quality in China-particularly for the poor! Soc Sci Med. 2004;59(7):1505-15.

41. Zhang J, Wang H, Wang Y, Xue H, Wang Z, Du W, Su C, Zhang J, Jiang H, Zhai $F$, et al. Dietary patterns and their associations with childhood obesity in China. Br J Nutr. 2015;113(12):1978-84.

\section{Ready to submit your research? Choose BMC and benefit from:}

- fast, convenient online submission

- thorough peer review by experienced researchers in your field

- rapid publication on acceptance

- support for research data, including large and complex data types

- gold Open Access which fosters wider collaboration and increased citations

- maximum visibility for your research: over $100 \mathrm{M}$ website views per year

At BMC, research is always in progress.

Learn more biomedcentral.com/submissions 